\title{
OS CAMPOS DE ATUAÇÃO PROFISSIONAL DA EDUCAÇÃO FÍSICA: UM OLHAR SOBRE O MERCADO DE TRABALHO NO INTERIOR DA PARAÍBA ${ }^{1}$
}

Prof. Dr. Eduardo Ribeiro Dantas

Departamento de Educação Física da Universidade Estadual da

Paraíba. Email: dudadantas@ig.com.br

\section{RESUMO}

Trata-se de um texto que discute a intervenção profissional na Educação Física brasileira, tendo em vista as interfaces entre o atual mercado do corpo e das práticas corporais, a formação profissional e os campos de atuação existentes no interior da região Nordeste, especialmente no Estado da Paraíba.

PALAVRAS-CHAVE: Intervenção, Formação, Mercado.

\section{ABSTRACT}

This text discusses professional intervention in Brazilian Physical Education, bearing in mind the interfaces between the present body and body practices market, the professional formation and the existing fields of action in Northeastern countryside in specially Paraiba state.

KEYWORDS: Intervention, Formation, Market

\footnotetext{
${ }^{1}$ Texto produzido para intervenção na mesa redonda "Os campos de atuação profissional da Educação Física: Educação, Saúde e Lazer" da I Semana de Educação Física Esporte e Lazer do CAMEAM e III Encontro Norte-Riograndense de Ciências do Esporte - CBCE/RN.
} 


\section{OS CAMPOS DE ATUAÇÃO PROFISSIONAL DA EDUCAÇÃO FÍSICA: UM OLHAR SOBRE O MERCADO DE TRABALHO NO INTERIOR DA PARAÍBA}

Qualquer olhar mais cuidadoso sobre a intervenção profissional na Educação Física brasileira não pode se limitar ao mero reconhecimento dos seus campos de atuação. Assim sendo, pretendo discutir aqui o mercado de trabalho dessa área, sem perder de vista a questão da formação profissional e o contexto da sociedade de consumo em que vivemos, onde a ampliação do mercado do corpo e das práticas corporais faz com que outras possibilidades de atuação profissional se configurem, trazendo com isso novos desafios e perspectivas ao cenário da Educação Física em nosso país.

Sem ter a pretensão de esgotar o assunto, procuro trazer como principal contribuição para sua reflexão nesta mesa redonda, dados sobre a situação de uma certa Educação Física que se encontra fora dos grandes centros urbanos da região Nordeste, ou seja, geograficamente distante do mercado de trabalho das ensolaradas capitais nordestinas. ${ }^{2}$ A partir de uma maior aproximação com o interior do Estado da Paraíba, onde resido e atuo profissionalmente, tento apontar caminhos para uma prática pedagógica em Educação Física que não esteja subordinada aos ditames do capital e sua lógica de mercado.

\section{A AMPLIAÇÃO DO MERCADO DO CORPO E DAS PRÁTICAS CORPORAIS}

A crítica ao crescimento desmedido do mercado do corpo ${ }^{3}$ e de suas práticas vem sendo realizada por diversas áreas do conhecimento no Brasil, principalmente aquelas que dialogam com as ciências humanas e sociais, além da arte, da filosofia e dos saberes populares. Na área da Educação Física, que apesar dos seus vínculos históricos com as ciências biomédicas já consegue produzir estudos consistentes a partir do referencial teórico das Humanidades, a reflexão sobre a mercadorização do corpo também acontece de forma mais constante e expressiva.

O aumento do interesse pelas questões do corpo e pelas práticas corporais na atualidade, por exemplo, é visto de forma desafiadora por Silva (2005), para quem a reabilitação do corpo no século XX revela não só uma positividade de difícil conquista na história da humanidade, como também, o reconhecimento da imensa subserviência e vitimização do corpo em nossa civilização.

Para a autora, a ampliação do mercado do corpo e de suas práticas vem acompanhada da necessidade de compreendermos as determinações que foram fundamentais na constituição desse fenômeno social, a partir de um olhar sobre os processos de mercadorização aos quais a cultura é submetida em uma sociedade de mercado como a nossa (SILVA, 2005).

\footnotetext{
${ }^{2}$ Não desejo com isso, estabelecer um juízo de valor entre a Educação Física realizada nas capitais e no interior dos estados brasileiros, valorizando uma certa Educação Física da capital em detrimento de outra do interior, ou vice-versa, mas sim, reconhecer suas peculiaridades, identificando o que as aproxima e o que as distancia no contexto atual.

${ }^{3}$ De acordo com Courtine (1995), o consumo de bens e serviços destinados à boa forma do corpo conheceu um desenvolvimento considerável nos anos 80, através do surgimento de impérios industriais que com atividades diversificadas ocuparam uma fatia significativa do mercado dos músculos.
} 
Como elemento significativo da multiplicação e pulverização das práticas corporais no mundo contemporâneo, ${ }^{4}$ destaco a busca pelo prazer e o bem estar dos indivíduos, bem como, a aventura e o desafio presentes na realização de certas práticas, como critérios orientadores para o consumo de bens e serviços destinados ao corpo na atualidade, o que movimenta o seu mercado, gerando de certa forma alterações significativas na intervenção profissional em Educação Física.

Segundo Lipovetsky (2007), o fenômeno do consumo nas duas últimas décadas passa a ser muito mais experiencial do que ostentatório. A lógica de diferenciação social que animava as análises do consumo na década de 70, deve ser relativizada, já que hoje em dia as satisfações emocionais, corporais, sensoriais, estéticas, relacionais, sanitárias, lúdicas e distrativas, são mais importantes que os produtos que consumimos para marcar uma determinada posição social.

Antes de tudo, o que é visado através do ato de compra, é o prazer da novidade, o arrebatamento existente em uma experiência de aventura. A figura que mais se assemelha à do consumidor contemporâneo, seja ele um consumidor compulsivo de produtos de luxo ou um praticante esporádico de esportes radicais, é a de um colecionador de experiências (LIPOVETSKY, 2007).

Dessa forma, talvez possamos interpretar a prática do Rugby e do Futebol Americano ${ }^{5}$ nas praias das cidades nordestinas expostas à globalização, como um fenômeno apoiado na lógica do consumo experiencial, onde o prazer da novidade é o que seduz muitos dos seus atletas. Lógica esta, que da mesma maneira seduz os praticantes de Rapel nas cidades do interior nordestino, cujos acidentes geográficos favorecem consideravelmente a sua prática. ${ }^{6}$

Seja no litoral ou no interior, o desejo pelo consumo de novas experiências movimenta o mercado do corpo, possibilitando o surgimento e a consolidação de certas práticas corporais, difíceis de serem vistas no cenário nordestino até bem pouco tempo atrás, cuja realização muitas vezes depende da aquisição de bens materiais não tão acessíveis a grande parte da população.

Entendo que o alargamento dessas práticas corporais traz maiores possibilidades de intervenção para os profissionais da Educação Física brasileira, principalmente se considerarmos as possíveis interfaces com a área do Lazer. De qualquer forma, seja em que campo for, a prática pedagógica em Educação Física tem que problematizar esse

\footnotetext{
${ }^{4}$ Práticas corporais como a ginástica aeróbica, o tai-chi, a musculação, o wind-surf, a hidroginástica, o skate, a capoeira, a street dance, a dança-afro, o rapel, entre tantas outras, que apesar de serem tratadas como “esportes” pelas mídias, já não atendem unicamente aos critérios clássicos da Sociologia do Esporte, tais como a competição, a comparação de desempenhos, a busca da vitória ou mesmo o recorde (BETTI, 2001).

${ }^{5}$ Em Natal e João Pessoa, assim como em outras cidades litorâneas do Nordeste, vemos hoje a proliferação de esportes como o Rugby e o Futebol Americano, sendo praticados em suas praias urbanas, lado a lado com as tradicionais peladas de futebol. Mesmo os municípios que não possuem praias, começam a presenciar o nascimento dos seus times, como é o caso de Campina Grande, casa do Borborema Troopers, time de Futebol Americano da cidade.

${ }^{6}$ Em Campina Grande, percebemos também um crescimento acentuado de grupos de pessoas que se reúnem para experienciar a prática do Rapel, aproveitando as potencialidades geográficas dos municípios circunvizinhos.
} 
fenômeno social, questionando, entre outras coisas, o consumismo desenfreado que muitas vezes se encontra por trás da lógica que o anima. ${ }^{7}$

\section{FORMAÇÃO E INTERVENÇÃO EM EDUCAÇÃO FÍSICA: O CASO DA UEPB}

Para pensarmos o mercado de trabalho da Educação Física fora dos grandes centros urbanos do litoral nordestino, precisamos considerar também os processos de formação profissional desses locais, compreendendo que eles não podem se tornar reféns do multifacetado mercado do corpo que se reconfigura a todo instante na sociedade de consumo contemporânea. Entendo que a formação profissional na Educação Física brasileira não deve ser regida pelo mercado de trabalho da área, mas sim, norteada pela reflexão epistemológica que acontece nos seus principais fóruns de debate, como o Colégio Brasileiro de Ciências do Esporte - CBCE.

Do ponto de vista quantitativo, em se tratando do sistema público de educação no interior dos Estados do Rio Grande do Norte e da Paraíba, podemos perceber nos últimos anos uma maior oferta de cursos para a formação profissional da população local, viabilizados pelos processos de expansão e interiorização do ensino superior no Brasil, que contam hoje tanto com o ensino presencial, quanto com a modalidade de Educação à Distância. ${ }^{8} \mathrm{O}$ próprio curso de Educação Física da Universidade Estadual do Rio Grande do Norte - UERN, que juntamente com a Secretaria Estadual do $\mathrm{CBCE} / \mathrm{RN}$ realiza este evento, é de certa forma fruto desses processos.

Mas para que a ampliação do ensino superior não se limite apenas a dados estatísticos nos relatórios educacionais dos órgãos governamentais, precisa resultar em recursos humanos qualificados para uma atuação direcionada ao interior da região Nordeste, a partir do atendimento às demandas locais e suas problemáticas específicas, nos já tradicionais e em novos campos de atuação profissional da Educação Física. Entendo que só assumindo de vez nossas competências e criando novos postos de trabalho para o desenvolvimento da região, é que poderemos absorver e manter nos campos de atuação da área os recursos humanos qualificados ano após ano nas universidades públicas do país, como a UEPB.

Em um período de trinta anos de existência, que celebrou em 26 de maio de 2008, data de aniversário de sua criação pela Resolução N ${ }^{\circ}$. 11/78 - CONSEPE da antiga Universidade Regional do Nordeste, o Curso de Educação Física da UEPB colocou no mercado de trabalho não só de Campina Grande, cidade onde se situa, cerca de 1.173 novos profissionais habilitados para o ensino da Educação Física nos mais diversos campos de atuação da área. ${ }^{9}$

\footnotetext{
7 Além do fato de que muitas vezes essas práticas são realizadas sem nenhum tipo de orientação profissional, podendo gerar maiores problemas aos seus praticantes, como casos já conhecidos de traumatismo craniano entre jogadores de Rugby, nos campeonatos e treinos organizados pelos times existentes no Nordeste.

${ }^{8}$ Destaco a criação recente da Universidade Federal Rural do Semi-Árido - UFERSA, além da expansão e interiorização dos Centros Federais de Educação Tecnológica - CEFETs e da Universidade Estadual da Paraíba - UEPB, através dos seus cursos presenciais e dos seus pólos EAD.

${ }^{9}$ Segundo uma estimativa de dados coletados na Pro-Reitoria de Ensino e Graduação da UEPB.
} 
Nessas três décadas de atuação junto à sociedade paraibana, em que formou 52 turmas às margens do açude de Bodocongó, ${ }^{10}$ o Curso de Educação Física da UEPB realizou diversas reformas curriculares, buscando acompanhar o dinamismo da realidade social, refletido, entre outros fatores, nas mudanças significativas do mundo do trabalho na sociedade contemporânea. Suas linhas de pesquisa e extensão vêm sendo pensadas tendo em vista o contexto global e local, contemplando atualmente as áreas da Educação Física adaptada, do Esporte e Lazer, da Saúde e da Educação.

Mesmo assim, a atuação profissional dos seus egressos acompanha uma característica comum no cenário da Educação Física brasileira, que é a tendência de ocupação de certos campos já tradicionais na área, como as escolas e as academias de ginástica.

Em um recente levantamento de dados sobre a atuação profissional de 29 egressos do curso no ano de 2005, realizado como etapa inicial de uma pesquisa que venho orientando na graduação sobre os motivos do abandono profissional na área, pude perceber que cerca de 1/3 desses egressos não estavam trabalhando com a Educação Física, assumindo funções diversas no mercado de trabalho, como as de técnico em enfermagem, policial militar e comerciante, entre outras.

Das linhas delineadas no Projeto Político-Pedagógico do curso, vemos que as da Saúde e Educação, com os seus campos clássicos de intervenção, representados pelas academias e escolas, recebem quase a totalidade dos egressos que atuam na área, fato este que revela ao mesmo tempo as possibilidades e os limites da atuação profissional nas linhas do Esporte e Lazer e da Educação Física adaptada.

Ainda quanto aos campos de atuação nas linhas da Saúde e Educação, é interessante notarmos que com relação as academias, temos uma parcela de profissionais donos dos seus próprios estabelecimentos, que ao terminarem o curso, voltam às suas cidades e montam os seus negócios. ${ }^{11}$ Já com relação à escola, nota-se um grande número de exalunos concursados, o que nos leva a questionar se o que os atrai para esse campo de atuação é a identificação com a área ou a estabilidade do emprego, já que um dos desafios que o magistério enfrenta atualmente, é o abandono da carreira docente, efetivado em muitos casos pela não identificação com o trabalho escolar.

\section{PERSPECTIVAS E DESAFIOS NA PRÁTICA PEDAGÓGICA EM EDUCAÇÃO FÍSICA}

Em primeiro lugar, considero que a prática pedagógica em Educação Física não acontece apenas na escola, estando o trabalho educativo presente em outros campos de intervenção. Gostaria porém, de me limitar neste momento, à reflexão sobre o cotidiano escolar, a partir da discussão sobre a questão do abandono do magistério público pelos professores de Educação Física e mesmo aqueles das demais áreas do conhecimento. ${ }^{12}$

\footnotetext{
${ }^{10}$ Açude cujas obras iniciadas em 1915, acompanhou o surgimento do bairro de Bodocongó, conhecido nacionalmente pela homenagem que recebeu da cantora Elba Ramalho em uma de suas músicas.

${ }^{11}$ Uma das características da UEPB é receber alunos de vários estados nordestinos, que ao terminarem os seus cursos, voltam aos seus estados. No próprio grupo investigado, temos 12 ex-alunos atuando na Paraíba, 1 no Rio Grande do Norte, 2 em Pernambuco, 3 na Bahia e 1 no Ceará.

${ }^{12}$ A título de informação, lembro que a Educação Física entrou recentemente nos Núcleos de Apoio à Saúde da Família - NASF, o que abre uma boa perspectiva para as interfaces com a área da Saúde Coletiva.
} 
Considerando os custos do investimento na formação de um professor, seja ele de que área for, entendo que um dos maiores desafios do campo educacional é evitar os vários tipos de abandono da prática docente, cujos processos se iniciam bem antes do pedido de exoneração por parte desse profissional. ${ }^{13}$

O abandono do magistério por parte dos professores vem sendo investigado não só na área da Educação Física brasileira. Lapo e Bueno (2003), por exemplo, mostram que esse fenômeno é geralmente um processo longo e gradativo, repleto de mecanismos pessoais e institucionais de que os docentes fazem uso, antes que ocorra o abandono definitivo.

Na área da Educação Física, o estudo de Santini e Molina Neto (2005), revela que as causas do desgaste profissional apontadas pelos professores são muitas, dentre elas, uma formação acadêmica insuficiente; a não participação na formulação de políticas educacionais; a multiplicidade de papéis sociais e profissionais exigidos e exercidos por eles; o ambiente de violência urbana e insegurança pessoal; os conflitos nas relações interpessoais; as condições materiais objetivas adversas e a dificuldade de lidar, política e epistemologicamente, com as críticas dirigidas pela comunidade escolar à Educação Física.

Fatores estes, que fazem com que os professores constituam suas estratégias de permanência dentro do ambiente escolar, tais como as faltas freqüentes, as licenças constantes, os pedidos de transferência e mesmo a perda do vínculo afetivo, que entendo ser umas das formas mais sutis e graves de abandono, já que o professor vai gradativamente perdendo o interesse pela sua profissão, até decidir abandoná-la por completo.

Creio que para combater esse quadro, a área da Educação Física já vem dando sinais bastante positivos, como os investimentos na formação continuada e a ressignificação de práticas profissionais historicamente consolidadas, a partir de mudanças no seu campo conceitual. Entendo porém, que ainda é necessário legitimarmos a prática pedagógica nas instituições de ensino, evitando a substituição das aulas da Educação Física escolar por atividades físicas apoiadas em um certo discurso reducionista da saúde humana, para que realmente tenhamos uma atuação profissional duradoura e compromissada com um projeto mais humano de sociedade.

\section{REFERÊNCIAS}

BETTI, M. Educação Física e sociologia: novas e velhas questões no contexto brasileiro. In: CARVALHO, Y. M.; RUBIO, K. Educação física e ciências humanas. São Paulo: Hucitec, 2001.

COURTINE, J. J. Os Stakanovistas do narcisismo. In: SANT’ANNA, D. B. (Org.). Políticas do corpo. São Paulo: Estação Liberdade, 1995.

LAPO, F. R.; BUENO, B. O. Professores, desencanto com a profissão e abandono do magistério. Cadernos de Pesquisa. São Paulo, n. 118, 2003.

\footnotetext{
${ }^{13}$ Somente no primeiro semestre de 2008, pude constatar através de consultas ao Diário Oficial do Estado da Paraíba, que 16 professores entraram voluntariamente com o pedido de exoneração.
} 
SANTINI, J.; MOLINA NETO, V. A síndrome do esgotamento profissional em professores de educação física: um estudo na rede municipal de ensino de Porto Alegre. Revista Brasileira de Educação Física e Esporte. São Paulo, v.19, n.3, jul./set, 2005.

SILVA, A. M.; DAMIANI, I. R. As práticas corporais na contemporaneidade: pressupostos de um campo de pesquisa e intervenção social. In: SILVA, A. M.; DAMIANI, I. R. (Orgs.). Práticas Corporais: Gênese de um movimento investigativo em Educação Física. Florianópolis: Nauemblu Ciência \& Arte, 2005. 